\title{
Current and wave dynamics in the shallow subtidal: implications to the ecology of understory and surface-canopy kelps
}

\author{
James E. Eckman ${ }^{1, *}$, David O. Duggins ${ }^{2}$, Christopher E. Siddon ${ }^{3,4}$ \\ ${ }^{1}$ Office of Naval Research, Code 322, 800 North Quincy Street, Arlington, Virginia 22217, USA \\ ${ }^{2}$ Friday Harbor Laboratories, University of Washington, 620 University Road, Friday Harbor, Washington 98250, USA \\ ${ }^{3}$ Department of Ecology and Evolutionary Biology, Brown University, Providence, Rhode Island 02912, USA \\ ${ }^{4}$ Present address: Juneau Center, School of Fisheries and Ocean Sciences; University of Alaska Fairbanks, \\ 11120 Glacier Highway, Juneau, Alaska 99801-8677, USA
}

\begin{abstract}
Current and wave properties were studied in the semi-protected waters of the San Juan Archipelago, Washington, at 6 shallow subtidal sites chosen to include a wide range of variability in exposure to both tidal currents and waves. Within each site, 4 to 6 plots measuring roughly 50 to $100 \mathrm{~m}^{2}$ each were established on nearly horizontal rock platforms at mean depths ranging from 6.1 to $11.0 \mathrm{~m}$, with most plots at mean depths of 7.0 to $9.2 \mathrm{~m}$. Plots were established nominally to minimize within-site variability in hydrodynamics, and were locations of several species of kelp (reported in a companion paper). For more than a year replicate measurements of flow and pressure (mean depth and wave signals) were collected at all sites in $2 \mathrm{~Hz}$ bursts $25 \mathrm{~cm}$ above the substratum, a height relative to understory kelps, providing a unique, detailed spatial and temporal characterization of a shallow subtidal hydrodynamic regime pertinent to these plants. Despite the intended similarity of plots within sites, local-flow microhabitat remained substantial at scales relative to understory plants, and largely ameliorated differences in tidal signals among most sites. Greater than $50 \%$ of the spatial variability in maximum tidal current speed, and 31 to $44 \%$ of the variance in the duration of periods of calm flow (speeds consistently $<20 \mathrm{~cm} \mathrm{~s}^{-1}$ ), occurred within sites at scales of meters, and not at the larger $(\mathrm{km})$ scales that separated sites. In contrast, wave effects at 7 to $11 \mathrm{~m}$ depth were predictable spatially. Significant wave impacts were recorded only at 2 sites characterized by a large, open fetch. Wave-dominated flows were recorded by replicate sensors multiple times within both of these sites, and the strongest instantaneous wave speeds approached 150 to $200 \mathrm{~cm} \mathrm{~s}^{-1}$. Maximum wavegenerated speeds recorded just above the substratum at these 2 sites were $\sim 2$ to $3 \times$ maximum tidal currents. These results help to explain patterns noted in concurrent studies of the population dynamics and morphology of several species of kelp.
\end{abstract}

KEY WORDS: Hydrodynamics $\cdot$ Kelp $\cdot$ Wave $\cdot$ Tidal current

\section{INTRODUCTION}

Hydrodynamic forces are known to be an important factor affecting the morphology and population dynamics of kelps. Studies carried out along exposed coastlines have shown that episodic periods of large waves exert a critical role in determining abundance and relative species composition of assemblages of surface canopy and understory kelps (e.g. Dayton \& Tegner 1984, Dayton et al. 1984, Seymour et al. 1989, Graham et al. 1997). The strength of currents or waves has been shown to determine morphological differences among widely separated sites in kelp blade morphology and biomechanical properties of 
plants (Koehl \& Alberte 1988, Gaylord et al. 1994, Johnson \& Koehl 1994, Denny et al. 1997, Gaylord \& Denny 1997, Kawamata 2001, Blanchette et al. 2002). Flow forces impact kelp morphology in a manner similar to their effects on the morphology of intertidal animals (Denny et al. 1985, Etter 1989, Pentcheff 1991, but see Denny 2000, Denny \& Blanchette 2000).

Most prior research on interactions between kelps and flow has been carried out in open-coast environments, exceptions being Koehl \& Alberte (1988) and Johnson \& Koehl (1994). In addition, detailed spatial measurements of flow forces relative to plant or animal ecology come primarily from the rocky intertidal region in open-coast environments (Denny 1985, Bell \& Denny 1994). Though comparatively well studied, these environments are physically extreme (i.e. end members) and patterns discovered there may indicate links between flow dynamics and biota that may not apply homologously in other marine environments in which kelp populations are well established. For example, detailed studies of flow forces in the intertidal have indicated that microtopography can greatly alter exposure of plants and animals to wave forces (Shanks \& Wright 1986, Bell \& Denny 1994). However, the extremely shallow flow depth during immersion and wave surge may accentuate the importance of local topography in the intertidal, and such effects might therefore be far less important subtidally. Moreover, wave forces presumably might play less of a role in determining kelp population dynamics and species composition in more protected, inland, subtidal regions.

Our research has examined the ecology of understory and surface canopy kelps in the shallow subtidal regions of the San Juan Archipelago, Washington (USA). This area generally is characterized by a dense coverage of overlapping fronds of diverse understory kelps (dominated by Agarum fimbriatum and Costaria costata), punctuated by occasional urchin barrens and clustered populations of the surface-canopy plant Nereocystis luetkeana. We report here on a detailed evaluation of the hydrodynamic environment of the shallow subtidal regions of this inland island archipelago. We obtained these data at an unprecedented resolution both spatially and temporally using a suite of instruments designed to discern the importance of tidal and wave-generated currents near the seafloor to understory plants. Among other findings, our results indicate the importance of apparently subtle microtopography in determining the exposure of understory kelps to the strong tidal currents that characterize certain sites within this archipelago, and the variability among widely spaced locales in exposure to stormgenerated wave forces.

\section{MATERIALS AND METHODS}

Study sites. Six study sites in the San Juan Archipelago (Fig. 1) were chosen to include a broad range of hydrodynamic regimes, incorporating variability in both tidal currents and storm-generated waves. These sites were locations of simultaneous studies of kelp population dynamics and ecology (Duggins et al. 2001, 2003, in this issue). Sites at Brown Island (Site B), Cantilever Point (Site C), Yellow Island (Site Y) and Minnesota Reef (Site M) were all located within San Juan Channel, or smaller channels or harbors connected to it. These 4 sites are sheltered by San Juan Island from strong southwesterly winds associated with fall, winter and spring storms, and therefore were expected to be comparatively free of large wave impacts. In contrast, sites at Whale Rocks (Site W) and Long Island (Site L) are located outside of San Juan Channel and are open to the Haro Strait and Strait of Juan de Fuca to the south and west. It was expected that these sites would experience more intense storm energy. The San Juan Archipelago experiences a mixed semi-diurnal tidal range, at times $>3 \mathrm{~m}$. This, coupled with the complex topography and distribution of islands within the archipelago, causes considerable spatial variability in tidal current intensity. The 6 sites were selected nominally so as to exploit a wide range of exposures to tidal currents.

Four to 6 regions (plots) of roughly 50 to $100 \mathrm{~m}^{2}$ each were defined within each site. Plots were created to

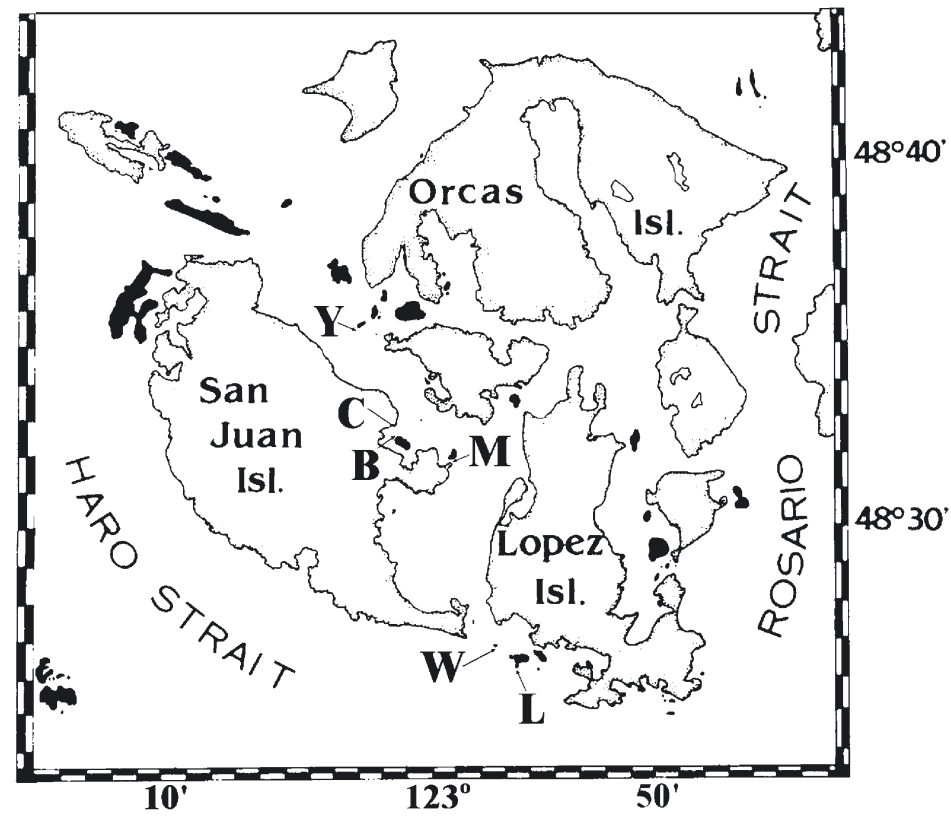

Fig. 1. San Juan Archipelago showing locations of 6 study sites. B: Brown Island; C: Cantilever Point; L: Long Island; M: Minnesota Reef; W: Whale Rocks; Y: Yellow Island 
allow studies of replicate plots of several species of kelp. Plots were established on nearly horizontal rock platforms at all sites, at depths ranging from 6.1 to $11.0 \mathrm{~m}$, with most plots at depths of 7.0 to $9.2 \mathrm{~m}$. As is characteristic of the shallow subtidal region in this area, these horizontal rock platforms existed within a more complex terrain of rocky shallows and steep ledges, located sometimes only meters from the plots. This narrow depth range was selected to minimize variability in penetration of light and wave energy to the bottom (both considered important to kelp populations, e.g. Dayton et al. 1999). It was thereby expected a priori that wide uniformity in environmental (light, nutrient, hydrodynamic) conditions would occur within each site, with maximal variability, primarily in hydrodynamic forcing, exhibited among sites.

Hydrodynamic measurements. The hydrodynamic properties of each study site were measured in situ using a suite of identical instrument complexes (Fig. 2). Each sensor in the instrument complex (2 thermistors, 1 pressure sensor [to measure depth and wave signals], and 2 bi-directional current sensors [oriented orthogonally to permit measurement of horizontal currents]) was wired to a battery-powered microcomputer (Tattletale ${ }^{\circledR}$ model 5F) contained inside the watertight pressure housing.

Each bi-directional current sensor was made of a rectangular strip of $0.5 \times 7 \mathrm{~cm}$ fiberglass (blank printed-circuit board) enclosed in a flexible, watertight silicone mold. A foil strain gauge wired into a Whetstone bridge-based circuit was glued onto each fiberglass strip near the base. The shape of the fiberglass strip encouraged flexure (and sensitivity to current) along only 1 axis, and the degree of bending of the strip (related monotonically to instantaneous current strength along that axis) determined resistance of the foil strain gauge, which was translated by circuitry into a potential measured by analog-to-digital converters in the data logger. The sensitivity of these current sensors to flow speed was tuned by gluing drag-producing bodies (plastic golf balls) near to the tip of each meter (Fig. 2).

Each current meter was calibrated individually at Skidaway Institute of Oceanography in a racetrack flume equipped with a laser-Doppler velocimeter (LDV). The LDV provided the 'ground-truth' standard measurement of velocity against which each meter was compared. Responses of each current sensor to velocity followed a power curve:

$$
u=a\left|x-x_{0}\right|^{b}
$$

where $u$ is velocity $\left(\mathrm{cm} \mathrm{s}^{-1}\right), x$ is a digital 'count' output by the data logger that varies with flexure of the sensor in flow, $x_{0}$ is the count logged at zero flow, and $a$ and $b$ are regression coefficients $(b \approx 0.5)$. Prior to calibrating sensors, each was tuned to be sensitive to maximum speeds of tidal currents and storm-generated waves (the latter approaching $200 \mathrm{~cm} \mathrm{~s}^{-1}$ ). A result of making meters sensitive to higher speeds was that they were neither precise nor accurate in resolving current speeds $<10 \mathrm{~cm} \mathrm{~s}^{-1}$. At least 6 different velocities $>10 \mathrm{~cm} \mathrm{~s}^{-1}$ were used in each regression. The median $\mathrm{r}^{2}$ of the 52 regressions calculated $( \pm x$ and $\pm y$ direction for each of $13 \mathrm{~m}$ used) was 0.994 . Therefore, meters were highly accurate at measuring flows above the minimum threshold of $\sim 10 \mathrm{~cm} \mathrm{~s}^{-1}$.

Instrument complexes were secured directly to the rock substratum using anchor bolts that had been set in the rock. Measurements of current velocity were obtained approximately 20 to $30 \mathrm{~cm}$ above the substratum, a height that closely matches that of thalli of the 3 species of understory kelp (Agarum fimbriatum, Costaria costata, Laminaria complanata) considered in studies of kelp mortality, morphology and biomechanics (Duggins et al. 2003). Instruments were programmed so that temperature, pressure and flow speed were sampled at $2 \mathrm{~Hz}$ for $128 \mathrm{~s}$ every $15 \mathrm{~min}$. The average current speed and direction, temperature, and pressure (translatable to depth) were recorded every $15 \mathrm{~min}$. In addition, the microcomputer was programmed to examine the variance of the $2 \mathrm{~Hz}$ pressure fluctuations, and to record all of the high-frequency measurements of flow speed and pressure (translatable to instantaneous wave signals) if pressure fluctuations indicated an influence by waves at depth. The threshold for a wave 'event' (that triggered recording of high-frequency data) was exceeded if the rootmean-square pressure fluctuation exceeded the standard deviation of a sine wave with an amplitude (at depth) of $28.3 \mathrm{~cm}$ (equivalent to a pressure fluctuation of $2.83 \times 10^{4} \mathrm{dyn}^{-2}$ ). At these depths, stormgenerated pressure fluctuations produced a mono-

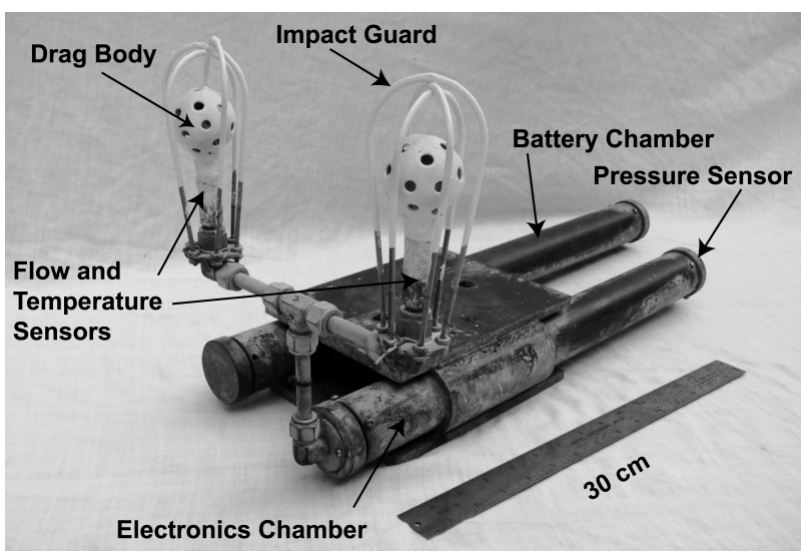

Fig. 2. Instrument complex used to measure current flow, temperature, and pressure (depth and wave-generated pressure fluctuations) 
chromatic wave pattern with a period typically 5 to $6 \mathrm{~s}$ (see 'Results'). Linear wave theory (e.g. Denny 1988) predicts that pressure signals of that amplitude, at $8 \mathrm{~m}$ depth and with a period of $5 \mathrm{~s}$, would be associated with maximum horizontal flow speeds of $\sim 26 \mathrm{~cm} \mathrm{~s}^{-1}$. This is less than the maxima in tidal current speeds at most sites (see 'Results'). Therefore, this threshold ensured that all important wave-dominated flows were recorded.

At least 1 instrument was deployed continuously at each site ( 2 at Sites W and L, which are the more waveexposed sites) throughout the duration of plant population studies, beginning in September, 1995 and ending in December 1996. In addition, to more fully categorize the variability in hydrodynamics within each site due to natural topographic exposure and shadowing, 2 to 5 additional meters were deployed within each site for periods ranging from 1 to $3 \mathrm{wk}$. These additional meters were rotated among sites throughout the study so that local (within-site) variability in currents was measured at all sites. The deployment of 4 to 6 meters for 1 to $3 \mathrm{wk}$ within each site ensured that much of the variability in the spring neap cycle of the mixed semidiurnal tide was included. Therefore, flow variability both within and among sites was well characterized.

Analysis of hydrodynamic data. Several hydrodynamic statistics pertinent to kelp ecology and population dynamics were extracted from the instrument data. First, it is worth noting that because meters were inaccurate at flow speeds $<10 \mathrm{~cm} \mathrm{~s}^{-1}$ it would be misleading to compare mean current speeds within and among sites. We therefore report percentile scores which are unaffected by the sensitivity threshold. The 75th, 90th, 95th and 99th percentiles of the 2 min average current strength are reported for each instrument during each deployment period. These statistics report the intensity of the strongest flows of importance to kelp, and should accurately reflect the relative variability in strengths of tidal signals within and among sites. In addition, for each instrument and deployment period, a frequency distribution of 'duration of calm' was generated. Duration of calm is defined as the time interval during which current speed remained below a threshold value, selected as $20 \mathrm{~cm} \mathrm{~s}^{-1}$. This threshold and frequency distribution may relate to the ability of mesograzers (browsing gastropods and isopods) to forage on and damage plant stipes (Duggins et al. 2001), for example. To compare variability within and among sites, percentile scores for current speed (99th percentile) and duration of calm (50th and 75th percentiles) were analyzed using 1-way ANOVA, with variance partitioning and a posteriori multiple comparisons tests using the GT2 method (Sokal \& Rohlf 1981).

The $2 \mathrm{~Hz}$ data from the pressure sensor were used to record the number of times during a deployment period that significant storm wave signals were detected. A storm wave 'event' was defined by the variance in the pressure signal, as described above. In addition to the number of wave 'events', high-frequency current-sensor data were analyzed to calculate the maximum wave velocity $\left(U_{\mathrm{w}-\mathrm{max}}\right)$ recorded during each $128 \mathrm{~s}$ wave record, and the maximum recorded during each instrument deployment period. The 128 s mean current was subtracted from the highfrequency wave data in calculating the maximum wave velocities.

Linear wave theory (e.g. Denny 1988) was used to further analyze the high-frequency pressure signals recorded during wave events. From sensor depth, wave period and pressure fluctuations, the predicted maximum horizontal flow speed during a $128 \mathrm{~s}$ wave record $\left(U_{\mathrm{w}-\mathrm{pred}}\right)$ was calculated according to:

$$
U_{\mathrm{w}-\text { pred }}=(\pi H / T)(\cosh (k s) / \sinh (k d))
$$

where $H$ is wave height, $T$ is wave period, $s$ is elevation above the bottom (here $s=25 \mathrm{~cm}$, the height of flow sensors), $d$ is depth, and $k$ is wave number (calculable from $T$ and $d$ ); and

$$
H=2 p_{\max }(\cosh (k d) /(\rho g \cosh (k s))
$$

where $p_{\max }$ is the maximum fluctuation in pressure from the mean during a wave event, $\rho$ the water density, and $g$ the gravitational acceleration.

$U_{\text {w-pred }}$ was compared with $U_{\text {w-max }}$ measured by the current sensors. This comparison was made to assess the accuracy with which in situ flow speeds can be predicted in shallow, topographically complex, subtidal environments using theory coupled with comparatively economical underwater wave (pressure) sensors.

\section{RESULTS}

In addition to the temporal variability in currents inherent to tides, there was substantial spatial variability in current speed within this topographically complex, shallow subtidal region. This variability was manifested both within sites (at scales $\leq 10$ s of meters) as well as among them (scales $>\mathrm{km}$ ). All sites except Site $\mathrm{C}$ experience occasional periods where tidal current strengths are strong $\left(>30 \mathrm{~cm} \mathrm{~s}^{-1}\right)$ at heights of understory kelps (Table 1, Fig. 3). Maximum tidal currents exhibit considerable variability among plots within most sites (at most sites a range of $\sim 2 \times$ ). This within-site variability largely obscures differences among widely separated sites in strengths of tidal current near the substratum. One-way ANOVA shows that the 99th percentile tidal currents varied significantly among sites $\left(F_{5,23}=4.58, \mathrm{p}=0.005\right)$; however, only Site C and Site W differed significantly ( $<<0.05)$. 
All other site pairs were statistically indistinguishable. Variance partitioning indicates that variability within a site (at scales $\leq 10$ s of meters) accounted for $57.3 \%$ of total variability in the 99th percentile of tidal currents, with $42.7 \%$ of total variance related to variability among sites.
Slack periods in the tidal cycle combined with topographically produced shading (e.g. up-current rocky shallows) are responsible for all sites experiencing periods of protracted calm flow (Fig. 4, Table 1). At all sites except Site C, $50 \%$ of the periods of calm flow $\left(<20 \mathrm{~cm} \mathrm{~s}^{-1}\right)$ lasted less than 1 tidal cycle $(\sim 12.2 \mathrm{~h}$ or

Table 1. Tidal current statistics. For location, letter code outside of parentheses refers to site (C: Cantilever Point; B: Brown Island; M: Minnesota Reef; Y: Yellow Island; L: Long Island; W: Whale Rocks); letter and number codes within parentheses describe a plot or location within site (kelp species and replicate number). NA: data not available

\begin{tabular}{|c|c|c|c|c|c|c|c|c|c|}
\hline \multirow[t]{2}{*}{ Date } & \multirow[t]{2}{*}{ Location } & \multirow{2}{*}{$\begin{array}{l}\text { Mean depth } \\
(\mathrm{cm})\end{array}$} & \multicolumn{4}{|c|}{ Percentile (speed, $\mathrm{cm} \mathrm{s}^{-1}$ ) } & \multicolumn{3}{|c|}{ Percentile (duration of calm, min) } \\
\hline & & & 75th & 90th & 95th & 99th & 50 th & 75th & 90th \\
\hline \multicolumn{10}{|c|}{ Longer-term records (mm/dd) } \\
\hline 09/26-12/04 & B (A-L-1) & 900 & $<10$ & 17.2 & 26.4 & 37.3 & 270 & 840 & 1410 \\
\hline $09 / 27-12 / 04$ & C (A-1) & 917 & $<10$ & $<10$ & $<10$ & 12.4 & 270 & 825 & 1440 \\
\hline $09 / 25-12 / 05$ & L (old bolt) & 767 & 11.0 & 17.9 & 21.6 & 33.4 & 120 & 232 & 315 \\
\hline $09 / 27-12 / 04$ & $\mathrm{M}(\mathrm{C}-1)$ & 615 & 18.4 & 32.1 & 39.3 & 49.3 & 67 & 105 & 150 \\
\hline $09 / 25-12 / 05$ & W (L-1) & 882 & 43.2 & 58.6 & 66.1 & 77.6 & 187 & 450 & 550 \\
\hline $09 / 25-11 / 21^{a}$ & $\mathrm{~W}(\mathrm{C}-2)$ & 827 & 38.9 & 55.4 & 63.7 & 76.2 & 90 & 180 & 345 \\
\hline 09/26-12/06 & Y (L-2 ) & 917 & $<10$ & 30.1 & 37.3 & 49.4 & 382 & 577 & 630 \\
\hline $09 / 26-12 / 06$ & $\mathrm{Y}(\mathrm{A}-1)$ & 813 & $<10$ & 24.0 & 28.9 & 39.2 & 600 & 615 & 645 \\
\hline \multicolumn{10}{|c|}{ Shorter-term, intra-site records } \\
\hline $11 / 07-11 / 16$ & $\mathrm{~B}(\mathrm{C}-1)$ & 882 & $<10$ & $<10$ & $<10$ & 50.0 & 112 & 1312 & 2782 \\
\hline $11 / 07-11 / 16$ & $\mathrm{~B}(\mathrm{~A}-2)$ & 890 & $<10$ & $<10$ & 23.9 & 35.2 & 435 & 1312 & 1515 \\
\hline 11/07-11/16 & B (C-2) & 837 & $<10$ & $<10$ & 28.2 & 41.8 & 270 & 840 & 1402 \\
\hline $11 / 07-11 / 16$ & B (A-L-1) & 913 & $<10$ & $<10$ & 24.9 & 37.3 & 45 & 1208 & 1342 \\
\hline \multicolumn{10}{|l|}{ Cantilever } \\
\hline $11 / 16-11 / 28$ & $\mathrm{C}(\mathrm{C}-2)$ & 710 & $<10$ & $<10$ & $<10$ & 15.9 & 1815 & 4440 & 9240 \\
\hline $11 / 16-11 / 28$ & $\mathrm{C}(\mathrm{C}-1)$ & 681 & $<10$ & $<10$ & $<10$ & $<10$ & 2497 & 14510 & 14520 \\
\hline $11 / 16-11 / 28$ & $\mathrm{C}(\mathrm{A}-\mathrm{L}-2)$ & 704 & $<10$ & $<10$ & $<10$ & 27.5 & 270 & 825 & 1440 \\
\hline $11 / 16-11 / 28$ & $\mathrm{C}(\mathrm{A}-1)$ & 913 & $<10$ & $<10$ & $<10$ & 12.4 & 2182 & 10765 & 10770 \\
\hline \multicolumn{10}{|l|}{ Long } \\
\hline 10/18-10/30 & L (N-1) & 903 & 31.2 & 43.6 & 49.6 & 56.6 & 120 & 232 & 307 \\
\hline $10 / 18-10 / 30$ & L (L-1) & 815 & $<10$ & $<10$ & 21.4 & 41.4 & 30 & 1410 & 3532 \\
\hline $10 / 18-10 / 30$ & L (old bolt) & 773 & $<10$ & 21.3 & 25.1 & 33.4 & 225 & 450 & 1470 \\
\hline $10 / 18-10 / 30$ & $\mathrm{~L}(\mathrm{~A}-\mathrm{C}-2)$ & 681 & 14.4 & 24.1 & 28.1 & 34.4 & 172 & 615 & 795 \\
\hline \multicolumn{10}{|l|}{ Minnesota } \\
\hline $07 / 27-08 / 17$ & M (summit) & 499 & 53.6 & 74.5 & 82.9 & 109.2 & 52 & 82 & 150 \\
\hline $07 / 27-08 / 17$ & M (A-L-2) & 702 & 19.1 & 26.8 & 30.4 & 37.7 & 187 & 315 & 510 \\
\hline $07 / 27-08 / 17$ & $M(C-1)$ & 638 & 34.2 & 40.5 & 43.3 & 49.3 & 67 & 105 & 150 \\
\hline $07 / 27-08 / 17$ & M (C-L-2) & 821 & 16.1 & 20.5 & 22.7 & 28.2 & 120 & 255 & 570 \\
\hline $07 / 27-08 / 17$ & $\mathrm{M}(\mathrm{N}-\mathrm{A}-1)$ & 847 & 16.6 & 20.3 & 22.6 & 26.5 & 22 & 315 & 510 \\
\hline $07 / 27-08 / 17$ & $\mathrm{M}(\mathrm{N}-2)$ & 885 & 26.3 & 35.5 & 38.9 & 44.3 & 405 & 487 & 517 \\
\hline \multicolumn{10}{|l|}{ Whale } \\
\hline $10 / 02-10 / 18$ & W (C-1) & 787 & 22.6 & 33.3 & 36.9 & 44.8 & 135 & 480 & 990 \\
\hline $10 / 02-10 / 18$ & W (N-2) & NA & 48.5 & 67.0 & 73.7 & 85.3 & 105 & 202 & 300 \\
\hline $10 / 02-10 / 18$ & W (L-2) & 1018 & 41.1 & 64.7 & 76.8 & 88.4 & 187 & 450 & 555 \\
\hline $10 / 02-10 / 18$ & W (N-1) & 716 & 24.4 & 32.3 & 36.9 & 46.1 & 30 & 135 & 270 \\
\hline $10 / 02-10 / 18$ & W (L-1) & 891 & 42.6 & 59.6 & 65.0 & 73.8 & 90 & 180 & 345 \\
\hline $10 / 02-10 / 18$ & W (C-2) & 827 & 43.2 & 62.3 & 71.3 & 80.4 & 120 & 300 & 450 \\
\hline \multicolumn{10}{|l|}{ Yellow } \\
\hline 09/26-10/02 & $\mathrm{Y}(\mathrm{C}-1)$ & 888 & $<10$ & 33.3 & 38.8 & 45.4 & 382 & 585 & 630 \\
\hline 09/26-10/02 & $\mathrm{Y}(\mathrm{A}-1)$ & 879 & $<10$ & 28.4 & 36.3 & 45.0 & 600 & 615 & 645 \\
\hline 09/26-10/02 & $\mathrm{Y}(\mathrm{C}-2)$ & 1105 & $<10$ & 13.8 & 21.9 & 25.8 & 570 & 675 & 1320 \\
\hline 09/26-10/02 & $\mathrm{Y}(\mathrm{L}-2)$ & 930 & $<10$ & 29.3 & 35.3 & 43.7 & 300 & 607 & 622 \\
\hline 09/26-10/02 & $\mathrm{Y}(\mathrm{A}-2)$ & 998 & 13.7 & 24.4 & 27.1 & 39.7 & 540 & 607 & 637 \\
\hline
\end{tabular}




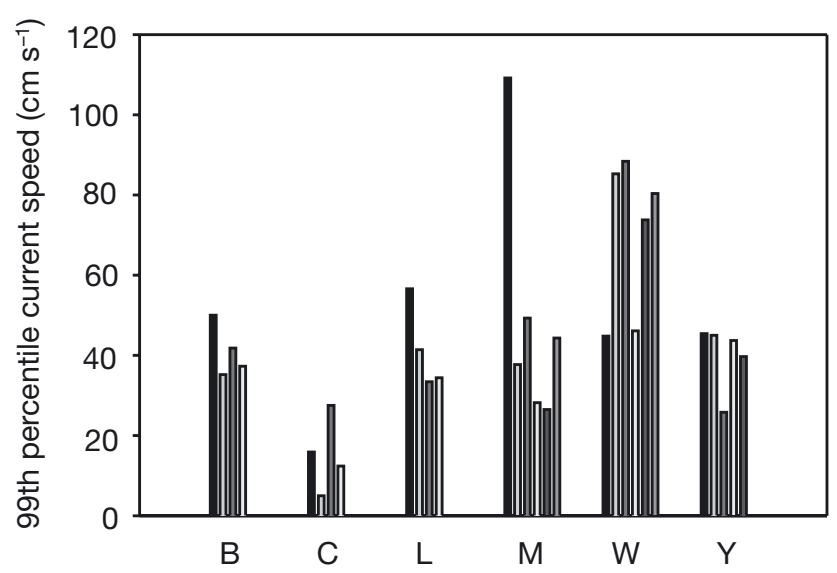

Fig. 3. 99th percentile of mean tidal current speed measured within plots at each site. See Fig. 1 for site abbreviations

$730 \mathrm{~min}$ ), and $75 \%$ lasted less than 2 tidal cycles. Most locations within Site C showed far longer periods of calm than occurred at other sites: $50 \%$ lasted more than 2 tidal cycles within 3 of 4 plots at Site C, and within 2 of 4 plots, $25 \%$ of calm periods (75th percentile) lasted more than $1 \mathrm{wk}$ (10080 min). Variance partitioning indicates that the larger-scale $(>\mathrm{km})$ site factor contributed far more to variability in the duration of calm than it did to variability in current speed near the substratum. Site differences explained $68.5 \%$ of variance in the 50th percentile, and $55.7 \%$ of variance in the 75 th percentile, of the duration of calm. Nevertheless, 1 of the 4 plots at Site C experienced considerably stronger currents than its nominal replicates (Fig. 3, Table 1), and it showed patterns of calm flow more like those recorded at the other 5 sites. This is more evidence of the high spatial variability in current strength exhibited within sites at heights pertinent to understory plants.

There was considerable variability among sites in exposure to storm-generated wave energy. On several occasions during fall through early spring, Sites W and L experienced significant wave energy continuously, from periods of hours to a few days (Table 2, Fig. 5). At levels of kelps, instantaneous flow speeds during wave events often exceeded $100 \mathrm{~cm} \mathrm{~s}^{-1}$ at Sites $\mathrm{W}$ and L, and sometimes exceeded $150 \mathrm{~cm} \mathrm{~s}^{-1}$. Sites at Cantilever Pt., Brown I. and Minnesota Reef never experienced significant wave activity (Table 2). Only 1 wave event (therefore lasting <30 min at the $822 \mathrm{~cm}$ depth of the sensor) was detected at Yellow Island, and the maximum instantaneous flow speed recorded during this event was only $54 \mathrm{~cm} \mathrm{~s}^{-1}$.

When significant wave energy was detected at Site W or L, it was recorded similarly by replicate instruments (Table 2, Fig. 5). There was, at times, up to $2 \times$ variability among replicate meters in maximum flow speeds produced by waves near the substratum. However, this level of variability was far less than that observed among sites.

High-frequency data recorded during storm events indicate that maxima in horizontal flow speeds match well with the peaks in instantaneous pressure fluctuations (Fig. 6). These plots illustrate that fluctuations in flow speeds at levels of kelps are extremely rapid during wave events - variations from zero net flow to $\approx 100 \mathrm{~cm} \mathrm{~s}^{-1}$ occur within 2 to $3 \mathrm{~s}$. Periods of stormgenerated waves typically were 5 to $6 \mathrm{~s}$.

Overall, maximum wave speeds measured by current sensors during wave events $\left(U_{\mathrm{w}-\mathrm{max}}\right)$ closely matched speeds predicted using pressure sensor data and linear wave theory ( $U_{\text {w-pred }}$ ) (Fig. 7 , Table 3 ). Data combined from 5 sensors deployed during 2 time periods at Sites W and L exhibit the expected linear relationship between the 2 parameters with a slope of 1 (Table $3, r^{2}=0.76$ ). It is noteworthy, however, that $24 \%$ of the total variance in $U_{w-m a x}$ was not predictable using pressure data and linear wave theory, and there was a significant intercept to the regression $(p=$
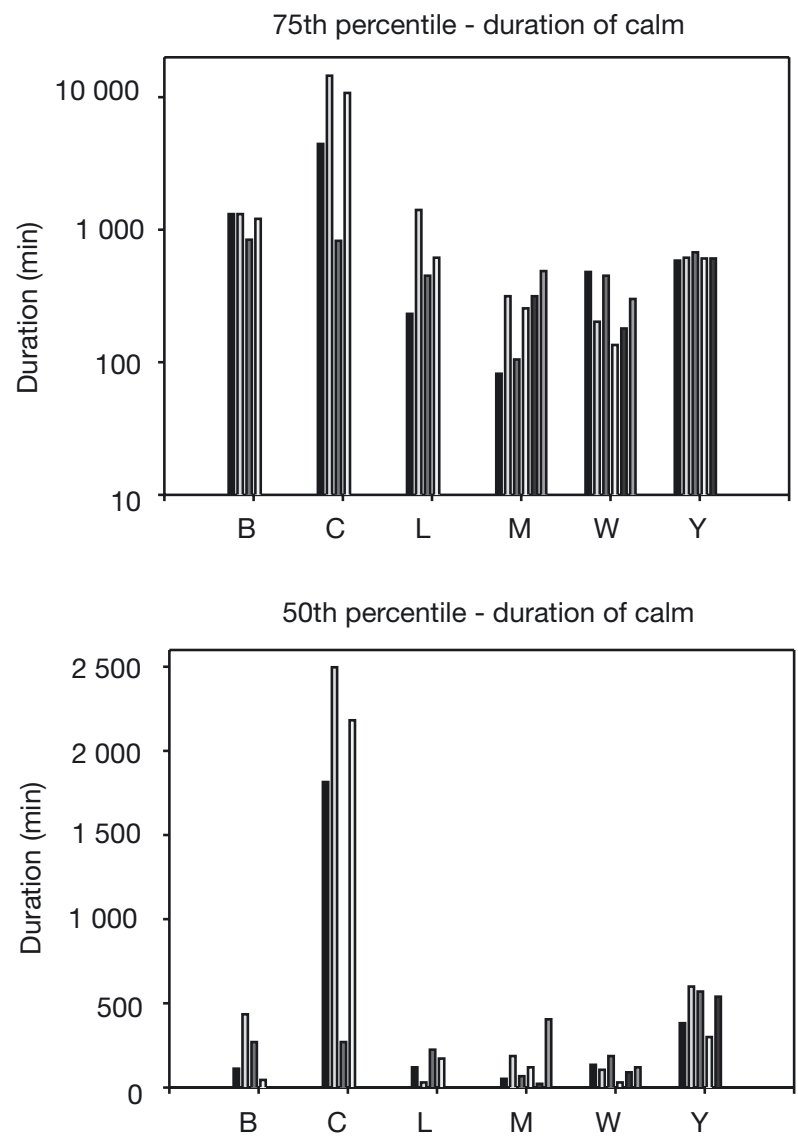

Fig. 4. 50th and 75th percentiles of the duration of periods of calm flow (mean current speed remaining $<20 \mathrm{~cm} \mathrm{~s}^{-1}$ ) measured within plots at each site. See Fig. 1 for site abbreviations 
Table 2. Summary of wave statistics. Site names abbreviated as C: Cantilever Point; B: Brown Island; M: Minnesota Reef; Y: Yellow Island; L: Long Island; W: Whale Rocks

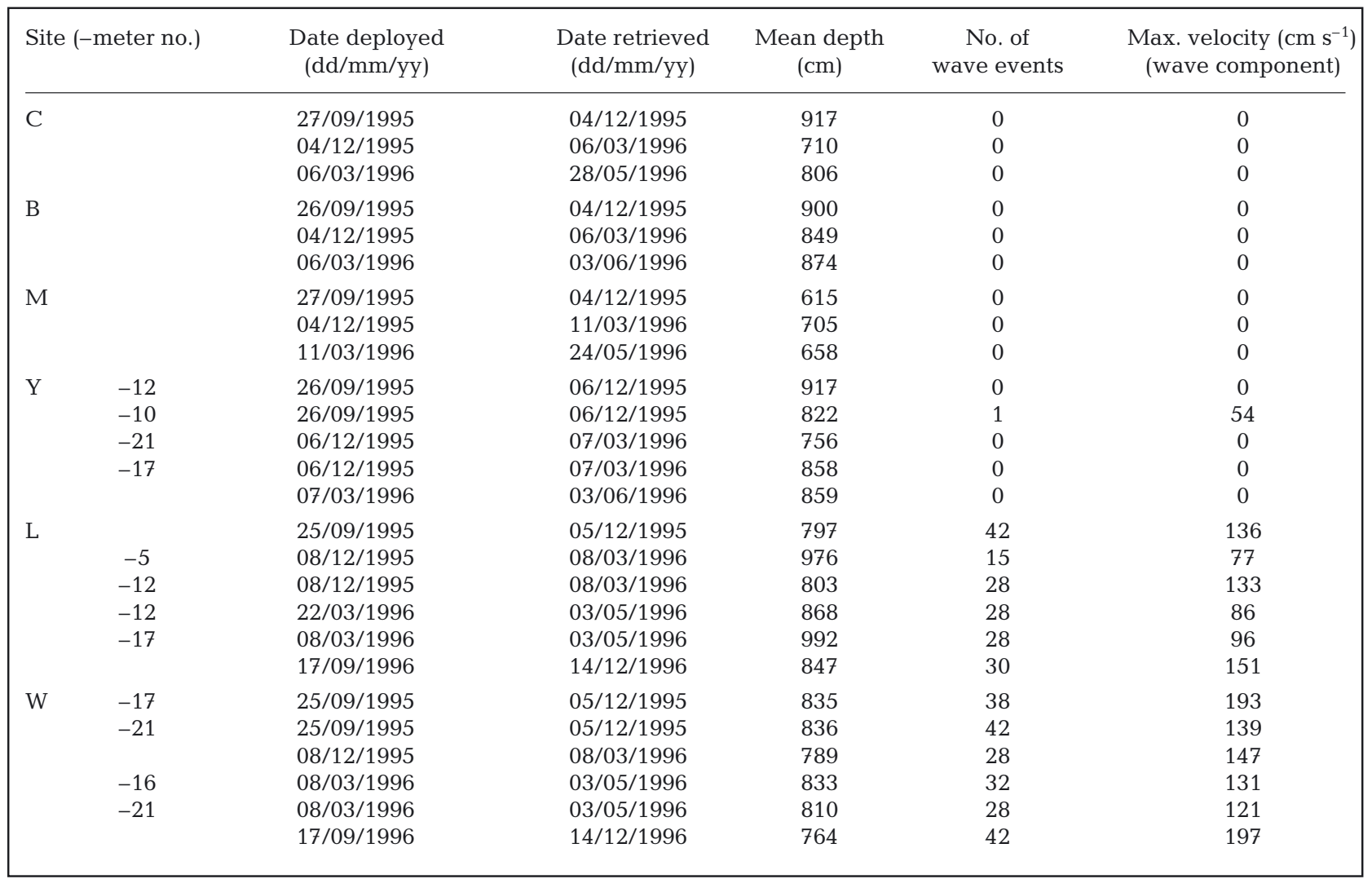

0.0001); observed maximum wave speeds were on average $\sim 13 \mathrm{~cm} \mathrm{~s}^{-1}$ higher than those predicted by theory. The fidelity of the match between observed and predicted wave speeds was strong generally, but varied greatly among plots and deployment periods (Table 3). In 3 of 5 instances, the 2 parameters matched closely $\left(\mathrm{r}^{2} \approx 0.85\right)$, whereas in 1 instance the match between the 2 terms was comparatively poor $\left(\mathrm{r}^{2}=\right.$ 0.29), though still statistically significant.

\section{DISCUSSION}

The plots set up for our studies of hydrodynamics (this paper), kelp morphology, biomechanics and population dynamics (Duggins et al. 2001, 2003) were established on broad, comparatively flat, and nearly horizontal rock platforms. Our methods attempted to minimize within-site variability in flow and variability both within and among sites in other environmental parameters (depth, light intensity, and presumably nutrient concentrations, given the strong tidal mixing in the San Juan Archipelago). It was therefore surprising to discover that $\sim 25 \mathrm{~cm}$ above the substratum, $>50 \%$ of the spatial variability in maximum tidal cur- rent speed, and 31 to $44 \%$ of the variance in duration of calm flow periods, was exhibited at scales of meters and not at the larger $(\mathrm{km})$ scales that separated sites. Rough topography has been shown to be responsible

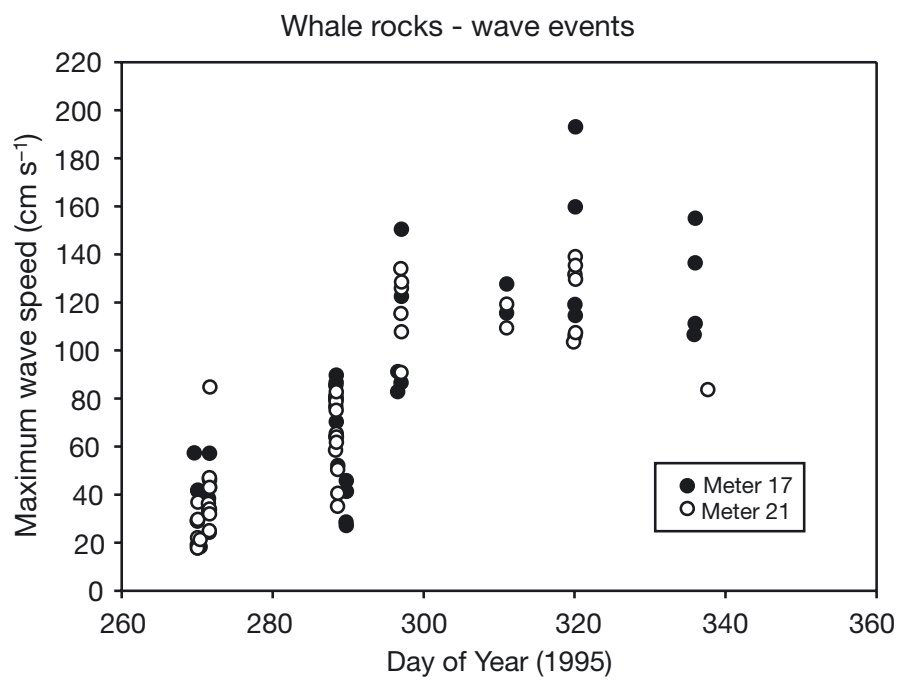

Fig. 5. Maximum wave speeds recorded during 2 min periods of wave-dominated flow by 2 instrument complexes deployed at Whale Rocks in the autumn of 1995 


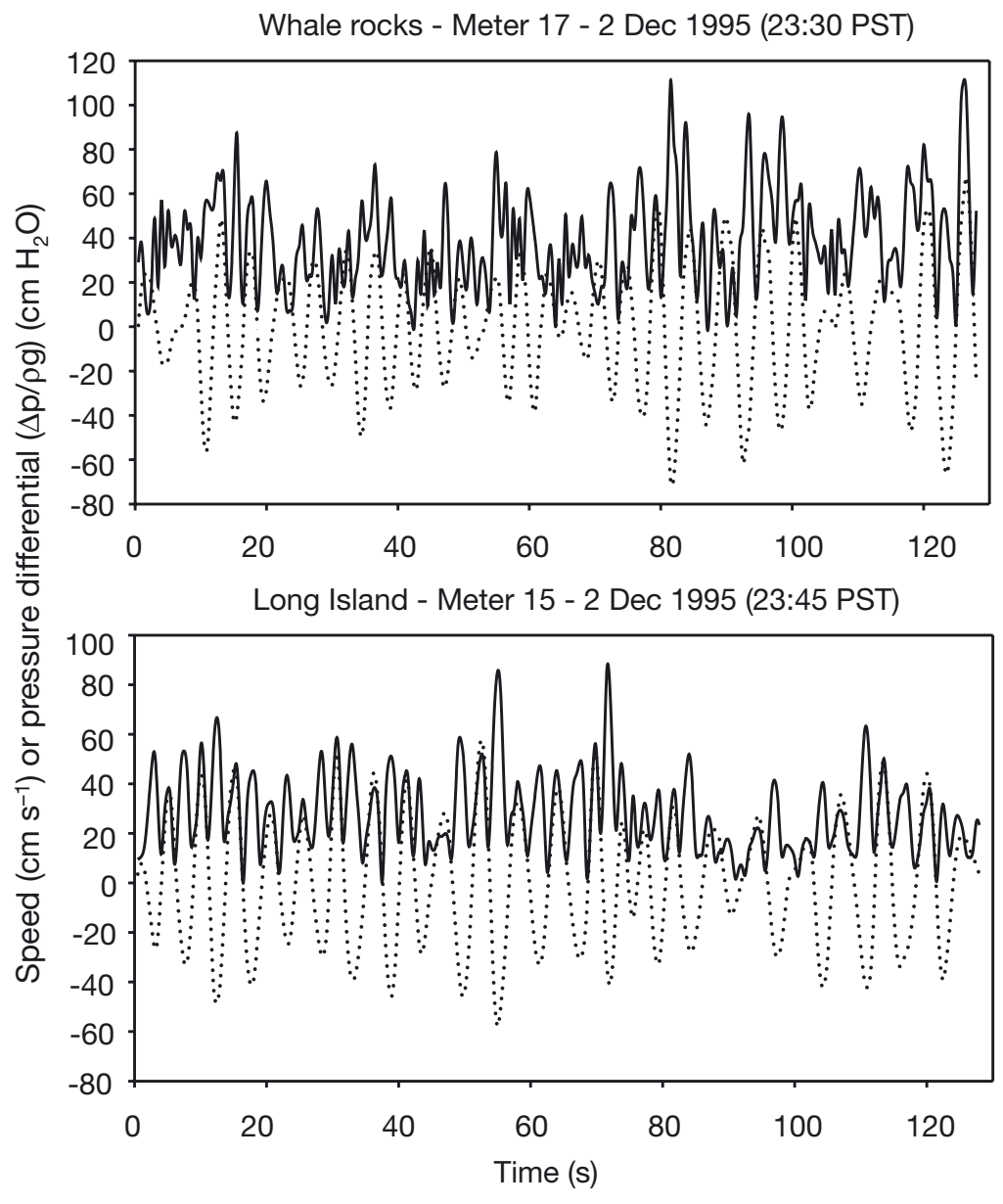

Fig. 6. High-frequency $(2 \mathrm{~Hz})$ records of wave-driven current speeds (solid lines) and pressure fluctuations (relative to a zero mean, dotted lines) recorded over separate $128 \mathrm{~s}$ periods by instrument complexes at Long Island and Whale Rocks. PST: Pacific Standard Time

spaced locales, and that microhabitat in shallow subtidal environments has the potential to greatly affect interactions between currents and a suite of macrobenthic organisms, including understory kelps, other macroalgae, and their predators.

Evidence that such effects can be important to kelps is obvious from our own studies. The rate of mortality of 3 understory species we studied (Agarum fimbriatum, Costaria costata, Laminaria complanata) was not related to differences among sites in tidal currents (Duggins et al. 2003), despite the fact that tides provided a regular, intense source of energy at some plots within several sites (Fig. 3). We suspect that a refuge from strong tidal flows, created by microhabitat, contributes to this decoupling. However, tidal energy does have a demonstrable impact on the structural morphology of 2 of these 3 species (Agarum and Costaria; Duggins et al. 2003).

The proposed importance of tidal-flow microhabitat to understory kelps is further supported by the contrasting patterns of mortality exhibited by the surface canopy plant, Nereocystis luetkeana, in the San Juan Archipelago. Small Nereocystis sporophytes rapidly grow too large to be influenced by the tidal flow microhabitats we detected just $25 \mathrm{~cm}$ above the substratum. It is therefore noteworthy that populations of Nereocystis are highly sensitive to tidal energy; they show patterns of mortality directly related to the interaction

for high local variability in exposure to wave-driven flows in the highly rugose, rocky intertidal region (Shanks \& Wright 1986, Bell \& Denny 1994), but it was remarkable to discover a similarly high variance in tidal flow energy in a narrow depth range of the subtidal, nominally selected to minimize such effects. This high local variability in flow close to the substratum, which can be expected to be relevant to understory plants and their macrobenthic predators (Duggins et al. 2001), is undoubtedly caused by local topographic variability within sites - either shadowing or channeling of flow caused by up-current topography. Far more extreme spatial variability in local topography is exhibited within our sites than existed among our nominal replicate plots. It should be obvious from our results, therefore, that local variability in topography can create flow microhabitat that can largely ameliorate differences in gross tidal energy imposed on widely of tidal currents with mesograzers upon them (Duggins et al. 2001). Our data indicate that differences in tidal currents among sites determine strong differences in abundance of small gastropods (Lacuna vincta) that graze on, and weaken, Nereocystis stipes, and that this may govern the observed variability among sites in mortality rates of Nereocystis. Therefore, when looked at together our data are consistent with the hypothesis that local flow microhabitats, particularly in regions subjected to strong tidal currents, may contribute to the structure and population dynamics of understory plants.

The importance of meso-grazer foraging to damage and mortality of Nereocystis (Duggins et al. 2001) highlights the value of our detailed documentation of not only the upper bound of current strength imposed by tides (Fig. 3, Table 1), but also its temporal pattern (Fig. 4, Table 1). Flume studies (Duggins et al. 2001, 


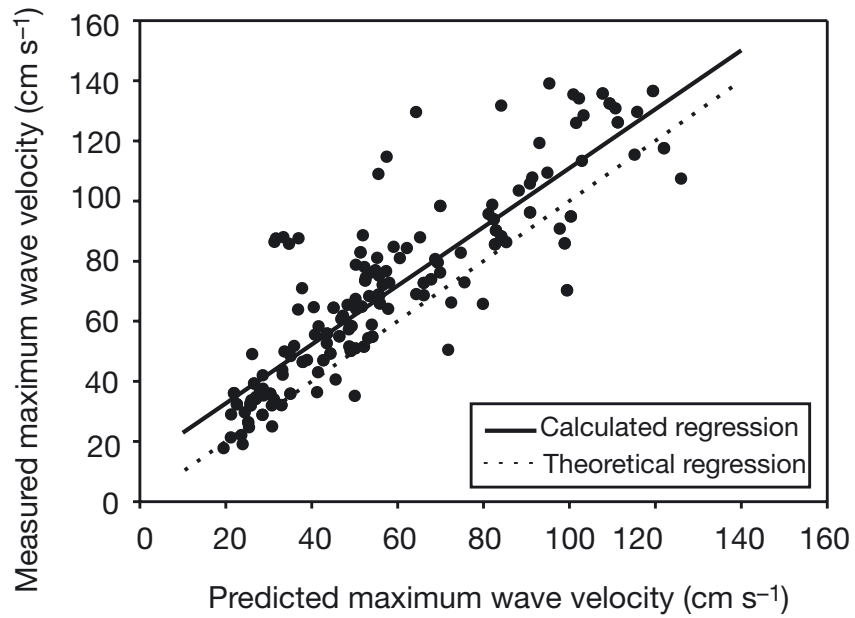

Fig. 7. Relationship between measured maximum speed of wave-generated currents and maximum speed predicted by linear wave theory using data collected by pressure sensors. Data are pooled from 5 instrument complexes deployed at Long Island and Whale Rocks. Theoretical (dotted line) and calculated (solid line) best-fit linear regressions are illustrated

their Fig. 8) indicate that the ability of gastropods to graze on kelp stipes is sensitive to changes in flow speed. Thus, flow shadowing, produced by up-current topography, for example, may significantly affect grazing on kelps. The potential importance of this topographic effect is illustrated in our calculations of 'duration of calm'. For example, $50 \%$ of calm-flow periods (i.e. with flow persistently $<20 \mathrm{~cm} \mathrm{~s}^{-1}$ ) at most plots at Site Y exceeded 500 min (Fig. 4B). This pattern was driven by the presence of a large shallow reef located just northward of our site, which shadowed it from tidal ebb. The temporal pattern of flow governed in part by this topographic feature no doubt contributed to the high meso-grazer abundance on stipes at Yellow Island, and the comparatively high mortality of Nereocystis there (Duggins et al. 2001). We therefore conclude that a detailed knowledge of the temporal history of flow in situ may be key to understanding some grazing pressures on kelps, and their mortality.
Although tidal forces may affect the morphology and biomechanics of understory kelps in the San Juan Archipelago, they have no demonstrable impacts on plant mortality (Duggins et al. 2003). In contrast, mortality, morphology and biomechanical attributes of understory plants are significantly affected by differences among sites in exposure to episodic, stormgenerated waves. The importance of wave forces to both understory and surface-canopy plants is well established in open-coastal environments (e.g. Dayton \& Tegner 1984, Dayton et al. 1984, Seymour et al. 1989, Graham et al. 1997, Kawamata 2001, Blanchette et al. 2002). Our results confirm that storm-generated waves are also important to plant population dynamics in an inland island archipelago as well.

In the San Juan Archipelago the impacts of strong wave energy at 7 to $11 \mathrm{~m}$ depth are much less predictable in time than are tidal currents, as the former are produced only by episodic storms, each of comparatively short duration, during late fall through early spring. However, the susceptibility of kelps to strong wave energy is predictable spatially — it was felt only at the 2 sites (Sites L and W) characterized by a large, open fetch to the south and west (Fig. 1), and high wave speeds were recorded by replicate sensors at both of these sites (Table 2) (cf. Bell \& Denny 1994). It appears, therefore, that storm energy at our study sites is not so obviously buffered by topographic microhabitat as is tidal flow. A similar pattern was noted in New England by Vadas et al. (1990) in their studies of survival of zygotes of the brown alga Ascophyllum nodosum. However, despite its comparative unimportance on the broad, flat, subtidal platforms studied here, the role of microtopography in mediating hydrodynamic effects of storm-generated waves cannot universally be discounted. In the intertidal, especially, where scales of bottom roughness are comparable to water depth during immersion and wave surge, microtopography can play an important role in determining exposure to wave forces and the population structure of epilithic organisms (Shanks \& Wright 1986, Bell \& Denny 1994).

Table 3. Regression statistics for relationship between maximum speed of wave-generated currents measured by 5 flow sensors (observed) and maximum speed predicted by linear wave theory using data collected by pressure sensor (predicted). ${ }^{*} \mathrm{p}<0.05$

\begin{tabular}{|c|c|c|c|c|c|c|c|}
\hline \multirow[t]{2}{*}{ Site } & \multirow{2}{*}{$\begin{array}{l}\text { Depth } \\
\text { (cm) }\end{array}$} & \multirow{2}{*}{$\begin{array}{c}\text { Date } \\
(\mathrm{mm} / \mathrm{dd} / \mathrm{yy})\end{array}$} & \multirow[t]{2}{*}{ Meter no. } & \multirow[t]{2}{*}{ Wave events } & \multicolumn{3}{|c|}{ Observed max. speed $=f$ (predicted max. speed) } \\
\hline & & & & & Slope (SE) & Intercept (SE) & $\mathrm{r}^{2}$ \\
\hline Whale Rocks & 805 & 09/25-12/05/95 & 17 & 42 & $0.992(0.069)$ & $12.0(5.36)^{*}$ & 0.834 \\
\hline Whale Rocks & 799 & $09 / 25-12 / 05 / 95$ & 21 & 42 & $1.17(0.072)^{*}$ & $0.10(5.03)$ & 0.861 \\
\hline Long Island & 755 & 09/25-12/05/95 & 15 & 42 & $0.978(0.059)$ & $9.28(3.98)^{*}$ & 0.871 \\
\hline Whale Rocks & 764 & 03/08-05/03/96 & 16 & 32 & $0.581(0.156)^{*}$ & $48.1(9.7)^{*}$ & 0.294 \\
\hline Long Island & 850 & $03 / 22-05 / 03 / 96$ & 12 & 28 & $0.876(0.097)$ & $17.1(4.64)^{*}$ & 0.748 \\
\hline Combined & & & & 186 & $0.979(0.040)$ & $13.1(2.6)^{*}$ & 0.761 \\
\hline
\end{tabular}




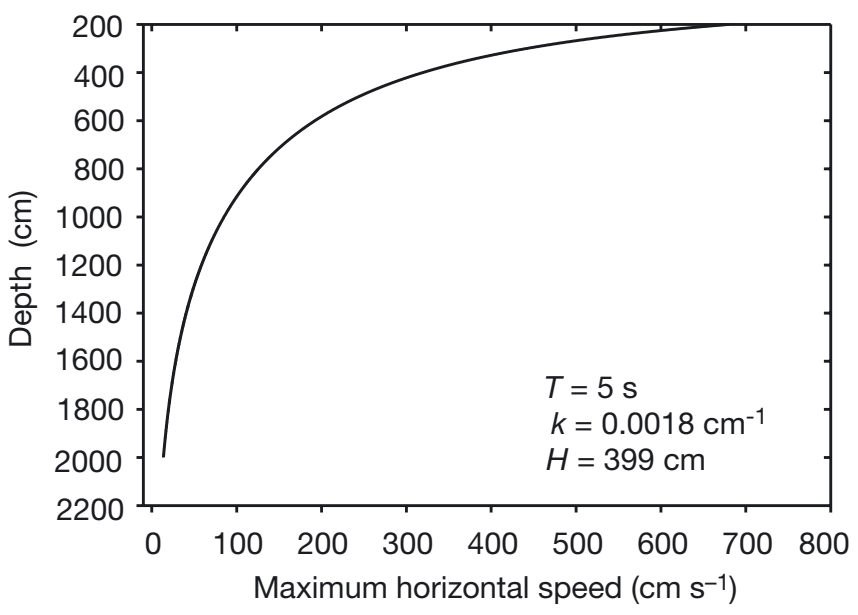

Fig. 8. Maximum horizontal current speed as a function of depth, predicted using linear wave theory for a hypothetical storm-generated wave typical of conditions measured at wave-exposed sites in the San Juan Archipelago. T: wave period; $k$ : wave number; $H$ : wave height

The maximum wave-generated speeds recorded at 7 to $11 \mathrm{~m}$ depth were $\sim 2$ to $3 \times$ the maximum tidal currents recorded just above the substratum (Tables 1 \& 2). Because drag forces on plants should scale to the square of flow speed (Schlichting 1979, Vogel 1981), this suggests that the strongest storm waves at Sites W and L should impose drag forces on understory plants $\sim 4$ to $9 \times$ those created by the strongest tidal currents. In addition, storm waves at these sites produce flow accelerations from essentially zero to as high as 150 to $200 \mathrm{~cm} \mathrm{~s}^{-1}$ within 1 to $2 \mathrm{~s}$ (Fig. 6), adding an additional acceleration force (though probably of smaller magnitude than the drag force, e.g. Denny 1988, Gaylord et al. 1994, their Table 2) to the potentially large wavedriven drag forces on plants. Therefore, it is hardly surprising that wave forces were important to the mortality and morphology of 2 species of understory kelps (Agarum fimbriatum, Costaria costata) in the San Juan Archipelago (Duggins et al. 2001), as has been demonstrated for understory and surface-canopy plants along more exposed coastlines (Dayton \& Tegner 1984, Dayton et al. 1984, Harris et al. 1984, Ebeling at al. 1985, Seymour et al. 1989, Molloy \& Bolton 1996, Graham et al. 1997, Blanchette et al. 2002). A similarly decisive role for waves in the dynamics of epilithic intertidal populations is, of course, well established (e.g. Dayton 1971, Paine \& Levin 1981, Sousa 1984, 1985, Shanks \& Wright 1986, Barry 1989, Etter 1989).

Although our data suggest that topographically created flow microhabitat may considerably ameliorate influences of tidal currents on understory plants in the San Juan Archipelago, depth should provide the primary refuge from wave exposure available for under- story plants. This has been demonstrated in open coastal locales as well (Dayton \& Tegner 1984, Dayton et al. 1984, Dayton 1985, Seymour et al. 1989). The depth refuge occurs because the maximum horizontal current speed produced by waves falls off non-linearly with depth (Fig. 8). This means of minimizing exposure of understory plants to wave-generated flow would, of course, ultimately be limited by the penetration of light, which declines exponentially with depth. Consequently, understory plants escaping storm wavegenerated forces at depth in more exposed locales may experience lower growth rates, and reproductive timing or output may thereby be delayed or reduced, potentially reducing plant fitness. Moreover, susceptibility to grazing attacks can also be expected to increase for plants inhabiting deeper waters (e.g. Lissner 1980, Witman 1987, Tegner et al. 1995, Kawamata 1998), and damage caused by grazers is an important cause of mortality of some kelps (Koehl \& Wainwright 1977, Tegner et al. 1995, Duggins et al. 2001).

It is worth noting that kelp sporophytes in the San Juan Archipelago germinate primarily during late spring and summer. This is a period during which an influence of waves is not felt at any of our sites and depths studied. Therefore, during their first several months of growth, kelp sporophytes have no exposure or capacity to respond to wave-generated forces. Consequently, it can be expected that only tidal signals, which are subject to strong microhabitat variability, would affect the relative investment by young kelp sporophytes in structural versus productive tissues. In fact, we noted a distinct dependence of plant morphology on current strength for the understory species studied (Duggins et al. 2003). Ultimately, therefore, many of the young plants growing in environments susceptible to waves may be poorly adapted to withstand winter storms due to an initial under-investment in structural tissue.

Our results (here, and in Duggins et al. 2001, 2003) help to reinforce the value of obtaining spatially and temporally detailed measurements of flow to help in interpreting biological patterns in shallow subtidal marine environments. The suite of paired, orthogonal, strain-gauge current sensors we used provided invaluable information on in situ microhabitat variability, as well as patterns of variability among widely spaced sites. However, these sensor systems are not available commercially, and are therefore unavailable to the general scientific community (nor are comparable, modestly priced sensors, to our knowledge). With respect to the critically important measures of wavedriven flow, our data indicate that a reasonable alternative to velocity sensors is to use bottom-mounted pressure sensors (sampled at high frequency) combined with wave theory. We noted a strong relation- 
ship between directly measured wave speeds and those predicted from pressure fluctuations and wave theory (Fig. 7). The scatter (variance) in the relationship illustrated in Fig. 7 probably was caused by topographically produced shadowing or channeling of waves, similar to that noted for tidal currents. This topographic effect may have been responsible for the poor correlation between predicted and observed wave speeds in 1 of 5 cases examined (Table 3 ). However, in general the fidelity of the match between observed and predicted wave speeds was strong. Because wave (pressure) sensors are commercially available, and affordable, this should be considered a useful alternative means of predicting wave impacts in subtidal environments. We expect, however, that this alternative and indirect means of predicting wave velocities and wave-generated forces would not work well in the intertidal (Denny et al. 1985), where the scale of bottom roughness is more comparable to flow depth during immersion, and where wave-driven flows will therefore be far more complex.

Acknowledgements. This research was supported by NSF award OCE-9314694 and ONR grant N00014-98-1-0260. We thank Dr. A. O. D. Willows (Director) and the staff of the Friday Harbor Laboratories for their support. Dr. Andy Trivett (Trivett Technologies) designed and built the wave and current sensors, and instructed the senior author in their use. Kamille Hammerstrom assisted greatly with diving.

\section{LITERATURE CITED}

Barry JP (1989) Reproductive response of a marine annelid to winter storms: an analog to fire adaptation in plants? Mar Ecol Prog Ser 54:99-107

Bell EC, Denny MW (1994) Quantifying 'wave exposure': a simple device for recording maximum velocity and results of its use at several field sites. J Exp Mar Biol Ecol 181: $9-29$

Blanchette CA, BG Miner and SD Gaines (2002) Geographic variability in form, size and survival of Egregia menziesii around Point Conception, California. Mar Ecol Prog Ser 239:69-82

Dayton PK (1971) Competition, disturbance, and community organization: the provision and subsequent utilization of space in a rocky intertidal community. Ecol Monogr 41: 351-389

Dayton PK (1985) Ecology of kelp communities. Annu Rev Ecol Syst 16:215-245

Dayton PK, Tegner MJ (1984) Catastrophic storms, El Niño, and patch stability in a southern California kelp community. Science 224:283-285

Dayton PK, Currie V, Gerrodette T, Keller BD, Rosenthal R, Ven Tresca D (1984) Patch dynamics and stability of some California kelp communities. Ecol Monogr 54:253-289

Dayton PK, Tegner MJ, Edwards PB, Riser KL (1999) Temporal and spatial scales of kelp demography: the role of oceanographic climate. Ecol Monogr 69:219-250

Denny MW (1985) Wave forces on intertidal organisms: a case study. Limnol Oceanogr 30:1171-1187
Denny MW (1988) Biology and the mechanics of the waveswept environment. Princeton University Press, Princeton, NJ

Denny MW (2000) Limits to optimization: fluid dynamics, adhesive strength and the evolution of shape in limpet shells. J Exp Biol 203:2603-2622

Denny MW, Blanchette CA (2000) Hydrodynamics, shell shape, behavior and survivorship in the owl limpet Lottia gigantea. J Exp Biol 203:2623-2639

Denny MW, Daniel TL, Koehl MAR (1985) Mechanical limits to size in wave-swept organisms. Ecol Monogr 55: 69-102

Denny MW, Gaylord BP, Cowen EA (1997) Flow and flexibility. II. The roles of size and shape in determining wave forces on the bull kelp Nereocystis luetkeana. J Exp Biol 200:3165-3183

Duggins DO, Eckman JE, Siddon CE, Klinger T (2001) The interactive roles of mesograzers and current flow in survival of kelps. Mar Ecol Prog Ser 223:143-155

Duggins DO, Eckman JE, Siddon CE, Klinger T (2003) Population, morphometric and biomechanical studies of three understory kelps along a hydrodynamic gradient. Mar Ecol Prog Ser 264:57-76

Ebeling AW, Laur DR, Rowley RJ (1985) Severe strom disturbances and reversal of community structure in a southern California kelp forest. Mar Biol 84:287-294

Etter RJ (1989) Life history variation in the intertidal snail Nucella lapillus across a wave-exposure gradient. Ecology 70:1857-1876

Gaylord B, Denny MW (1997) Flow and flexibility. I. Effects of size, shape and stiffness in determining wave forces on the stipitate kelps Eisenia arborea and Pterygophora californica. J Exp Biol 200:3141-3164

Gaylord B, Blanchette CA, Denny MW (1994) Mechanical consequences of size in wave-swept algae. Ecol Monogr 64:287-313

Graham MH, Harrold C, Lisin S, Light K, Watanabe JM, Foster MS (1997) Population dynamics of giant kelp Macrocystis pyrifera along a wave exposure gradient. Mar Ecol Prog Ser 148:269-279

Harris LG, Ebeling AW, Laur DR, Rowley RJ (1984) Community recovery after storm damage: a case of facilitation in primary succession. Science 224:1336-1338

Johnson AS, Koehl MAR (1994) Maintenance of dynamic strain similarity and environmental stress factor in different flow habitats: thallus allometry and material properties of a giant kelp. J Exp Biol 195:381-410

Kawamata S (1998) Effect of wave-induced oscillatory flow on grazing by a subtidal sea urchin Strongylocentrotus nudus (A. Agassiz). J Exp Mar Biol Ecol 224:31-48

Kawamata S (2001) Adaptive mechanical tolerance and dislodgement velocity of the kelp Laminaria japonica in wave-induced water motion. Mar Ecol Prog Ser 211: 89-104

Koehl MAR, Alberte RS (1988) Flow, flapping, and photosynthesis of Nereocystis luetkeana - a functional comparison of undulate and flat blade morphologies. Mar Biol 99: 435-444

Koehl MAR, Wainwright SA (1977) Mechanical adaptations of a giant kelp. Limnol Oceanogr 22:1067-1071

Lissner AL (1980) Some effects of turbulence on the activity of the sea urchin Centrostephanus coronatus Verrill. J Exp Mar Biol Ecol 48:185-193

Molloy FJ, Bolton JJ (1996) The effects of wave exposure and depth on the morphology of inshore populations of the Namibian kelp, Laminaria schinzii Foslie. Bot Mar 39: $525-531$ 
Paine RT, Levin SA (1981) Intertidal landscapes: disturbance and the dynamics of pattern. Ecol Monogr 51:145-178

Pentcheff ND (1991) Resistance to crushing from wave-borne debris in the barnacle Balanus glandula. Mar Biol 110: 399-408

Schlichting H (1979) Boundary-layer theory. McGraw-Hill, New York

Seymour RJ, Tegner MJ, Dayton PK, Parnell PE (1989) Storm wave induced mortality of giant kelp, Macrocystis pyrifera, in southern California. Estuar Coast Shelf Sci 28: 277-292

Shanks AL, Wright WG (1986) Adding teeth to wave actionthe destructive effects of wave-borne rocks on intertidal organisms. Oecologia (Berl) 69:420-428

Sokal RR, Rohlf FJ (1981) Biometry. WH Freeman, San Francisco

Sousa WP (1984) Intertidal mosaics: patch size, propagule

Editorial responsibility: Kenneth Tenore (Contributing Editor), Solomons, Maryland, USA availability, and spatially variable patterns of succession. Ecology 65(6):1918-1935

Sousa WP (1985) The role of disturbance in natural communities. Annu Rev Ecol Syst 15:353-391

Tegner MJ, Dayton PK, Edwards PB, Riser KL (1995) Sea urchin cavitation of giant kelp (Macrocystis pyrifera C. Agardh) holdfasts and its effects on kelp mortality across a large California forest. J Exp Mar Biol Ecol 191:83-99

Vadas RL, Wright WA, Miller SL (1990) Recruitment of Ascophyllum nodosum - wave action as a source of mortality. Mar Ecol Prog Ser 61:263-272

Vogel S (1981) Life in moving fluids. Princeton University Press, Princeton, NJ

Witman JD (1987) Subtidal coexistence: storms, grazing, mutualism, and the zonation of kelps and mussels. Ecol Monogr 57(2):167-187

Submitted: November 3, 2002; Accepted: August 18, 2003

Proofs received from author(s): December 1, 2003 